\title{
Drug Prevention by Increasing Self-Esteem: Influence of Teaching Approaches and Gender on Different Consumption Groups
}

\author{
Heyne Thomas ${ }^{1, *} \&$ Bogner Franz X. ${ }^{2}$ \\ ${ }^{1}$ Didactics of Biology, University of Würzburg, D-97074 Würzburg, Germany \\ ${ }^{2}$ Centre of Maths \& Science Education (Z-MNU), Institute of Biology Didactics, University of Bayreuth, D-95447 \\ Bayreuth, Germany \\ "Corresponding author: Didactics of Biology, University of Würzburg, Matthias-Lexer-Weg, Geb. 25, D-97074 \\ Würzburg, Germany \\ Tel: 49-931-318-3789 \\ E-mail: thomas.heyne@biozentrum.uni-wuerzburg.de
}

Received: November 30, 2012

Accepted: January 2, 2013 Online Published: January 9, 2013

doi:10.5430/wje.v3n1p1

URL: http://dx.doi.org/10.5430/wje.v3n1p1

The study was supported by the Bavarian State Ministry of Education as well as by the University of Bayreuth.

\begin{abstract}
Our study focused on an educational intervention designed to increase the self-esteem of low-achieving eighth graders. The intervention was a substance-specific life skills program built upon teacher-centered versus student-centered teaching methods. A cluster analysis identified four consumption groups prior to the intervention: A potentially curious cluster (PC), a currently curious cluster (CC), an experimenter cluster (EP) and a consumer cluster (CO). Self-esteem was measured three times in a pre-, post- and retention test design. The in terms of percentage biggest PC cluster only responded positively. A consistent increase was detected among both different teaching methods and both genders. Thus, self-esteem as an important psychological construct of physical well-being could be influenced positively by many students in the context of a substance-specific life skills program. Educational consequences to increase the efficiency of scholastic measures are discussed.
\end{abstract}

Keywords: self-esteem; life skills; drug prevention; consumption groups; teaching approaches

\section{Introduction}

1.1 Modern Drug Prevention Programs Integrate Drug-Specific Contents as well as the Development of Life Skills

School-based prevention programs are of great importance in the prevention of substance abuse amongst teens. Teens generally do not always behave rationally with regard to health-risk behaviour and, therefore, may need specific educational intervention (Freitag, Kähnert, \& Hurrelmann, 1999; Kolip, 1999; Mittag \& Jerusalem, 1999). In most syllabi, acquisition of knowledge about legal drugs is recommended, often by emphasizing the avoidance of illegal drugs, defensive attitudes towards peer pressure, and the development of self-esteem via the acquisition of appropriate life skills. According to Brandon (2001) self-esteem is confidence in our ability to think, confidence in our ability to cope with the challenges of life and confidence in our right to be happy, the feeling of being worthy. Life skills point to a similar direction and are defined as abilities that enable an individual to deal effectively with the demands and challenges of everyday life (World Health Organization, 1994). Life skills programs, therefore, exist in many countries. They combine substance-specific and more general measures. Such programs intervene using the cognitive competencies, social communication and self-competency of students (Kähnert, 2003). Programs within this context have often showed positive effects on drug abuse patterns in terms of increased knowledge, reduction in consumption, delayed consumption and attitude change (G.J. Botvin, Baker, Dusenbury, E.M. Botvin, \& Diaz, 1995; Botvin \& Dusenbury, 1998; Cuijpers, 2002; Durlak, 1995; Gottfredson, Jones, \& Gore, 2002; Miller, 1988; Scheier, Botvin, \& Griffin, 2001; Tobler et al., 2000).

\subsection{High Self-Esteem as Protective Factor against Different Negative Influences}

Effective educational approaches address students' self-esteem as well as content because self-esteem is regarded as 
a major indicator of physical well-being in teens (Harter, 1999; Rosenberg, 1986). The literature presents a high level of self-esteem as a key element in coping with peer pressure, poor school performance and negative emotional well-being (Harter, 1990; Hattie, 1992; Rosenberg, 1986; Zimmerman, Copeland, Shope, \& Dielman, 1997). Low self-esteem correlates with high suicide rates, delinquency and depression (Bynner, O'Malley \& Bachman, 1981; Harter, 1986; Kazdin, French, Unis, \& Esveldt-Dawson, 1983; Reinherz et al., 1989; Rosenberg, Schooler, \& Schoenbach, 1989; Wells \& Rankin, 1983). Cross-sectional studies have consistently demonstrated a relationship between self-esteem and drug abuse (Neumark-Sztainer, Story, French, \& Resnick, 1997; Newcomb, Maddahian, \& Bentler, 1986; Selnov, 1985; Stacy, Newcomb, \& Bentler, 1992). Botvin, Griffin, Paul, and Macaulay (2003) and Kähnert (2003) reported the positive effect on self-esteem of attitude change and/or a decline in drug consumption in their life skills programs. Longitudinal studies by Hirsch and DuBois (1991) as well as by Zimmerman et al. (1997) described individuals whose self-esteem had changed over a period of four or two years, and simultaneously Zimmerman et al. (1997) found a correlation between self-esteem and alcohol abuse. Teens with low self-esteem showed the highest alcohol abuse. The moderate and high-score group, in contrast, showed low or no alcohol consumption over a four-year period while the high-score group consistently showed the lowest abuse level at any test schedule. Furthermore, a study of the German Federal Centre for Health Education (2004) concerning teens affinity for drugs showed drug experience as a sequential exposure process to illegal drugs. Half of the teens who reported alcohol abuse ultimately moved on to the use of cannabis.

1.3 Conventional Substance-Specific Life Skills Programs do not Consider Heterogeneity of Students with Regard to their Consumption Behaviour and Attitude

Following Zimmerman et al. (1997), who revealed the importance of a strong self-esteem with regard to a low substance abuse, we developed a nine-hour substance abuse prevention life skills program for low achieving eighth graders within the framework of the existing syllabus. A male educator conducted the interventions in all classes. The drug-specific life skills program should influence self-esteem of students positively, but we wanted to examine potential changes in self-esteem particularly in relation to different consumption groups. Thus, we quantified students' consumption behaviour and attitude and identified following distinct clusters: the potentially curious sample, labelled as cluster 1 (PC), the currently curious sample, labelled as cluster 2 (CC), the experimenter sample, labelled as cluster 3 (EP) and the consumer sample, labelled as cluster 4 (CO).

\subsection{The Question of the Appropriate Teaching Method}

Our program consisted of two parts: an initial drug-specific module concerning the gateway drug cannabis, and a subsequent substance-nonspecific one, targeting self-esteem and resistance self-efficacy (Table 1). Student-centered or teacher-centered teaching approaches were provided when teaching the substance-specific content of cannabis. The question of the appropriate teaching method arises, because students often have a clearly defined standpoint on drugs. A constructivist student-centered approach provides a launching pad for students independently, individually and actively constructing new knowledge, while in a teacher-centered approach knowledge is transferred only as abstract information to students (Duit, Gropengießer, \& Kattmann, 2005; Kember \& Gow, 1994). Thus, in a second step, we examined whether the consumption groups react to the self-esteem measures in a more positive and rapid manner due to our student-centered constructivist approach.

\subsection{Hypotheses}

We developed four hypotheses:

1) This specific drug prevention program reveals to positive changes in self-esteem of students.

2) The determined consumption groups respond differently to the self-esteem treatments.

3) Boys and girls may react differently to the self-esteem treatments due to the presence of a male educator.

4) Constructivist student-centered approaches influence the effectiveness of the self-esteem treatments more strongly than teacher-centered methods.

\section{Methodology}

\subsection{Sample}

A total of 282 Bavarian students (159 boys, 123 girls) from 16 classes participated in our study. They were low-achieving eighth graders; their age ranged between 13 and 17 years $(\mathrm{M}=13.9 ; \mathrm{SD}=0.71)$. 


\subsection{Prevention Approach, Quasi-Experimental Design and Independent Variables}

Peer-based interventions (social life skills programs) and affectively focussed knowledge interventions were used as components in designing the substance-specific life skills program (Tobler, 1986). The teaching unit consisted of nine lessons in full compliance with the existing syllabus. In order to keep the quality of implementation constant, in accordance with Hansen, Graham, Wolkenstein, and Rohrbach (1991), a male educator conducted the interventions in all classes.

The study followed a quasi-experimental design and focussed on two different teaching methods (student-centered vs. teacher-centered) in the substance-specific part by targeting both psychological constructs in the substance-nonspecific part (Table 1). The substance-specific content imparted knowledge about the gateway drug cannabis for a period of three lessons. Health risks, effects on road traffic, the penalty consequences, and special characteristics of the drug were elaborated (Heyne \& Bogner, 2012). The substance-nonspecific content focussed on strengthening self-esteem and resistance self-efficacy of the students for a period of six lessons. A control group $(n=$ 46) served for test assessment and exclusion of other potential external influences (Lienert \& Raatz, 1998). We did not carry out a post-test $\left(\mathrm{T}_{1}\right)$ with the control group, arguing that only middle-term changes of self-esteem were of interest to our study, and hence we only measured at the end of our study $\left(\mathrm{T}_{3}\right)$.

Table 1: Quasi-Experimental Design of the Study

\begin{tabular}{|c|c|c|c|c|}
\hline \multirow[b]{2}{*}{ Time } & \multicolumn{4}{|c|}{ Groups } \\
\hline & $\begin{array}{c}\text { Instruction } 1 \\
(\mathrm{G} 1) \\
\end{array}$ & $\begin{array}{c}\text { Instruction } 2 \\
(\mathrm{G} 2) \\
\end{array}$ & $\begin{array}{c}\text { Instruction } 3 \\
\text { (G3) }\end{array}$ & Control \\
\hline \multicolumn{5}{|c|}{ Preceding substance-specific content (three lessons) } \\
\hline $\begin{array}{l}45 \mathrm{~min} \\
90 \mathrm{~min}\end{array}$ & $\begin{array}{c}\text { Pre-lesson } \\
\text { Conventional } \\
\text { learning at } \\
\text { workstations } \\
\text { (student-centered) }\end{array}$ & $\begin{array}{c}\text { Pre-lesson } \\
\text { Guided learning } \\
\text { at workstations } \\
\text { (student-centered } \\
\text { guided) }\end{array}$ & $\begin{array}{c}\text { Pre-lesson } \\
\text { Teacher-centered } \\
\text { lesson } \\
\text { (contents of the } \\
\text { workstations) }\end{array}$ & -- \\
\hline $\begin{array}{l}90 \mathrm{~min} \\
180 \mathrm{~min}\end{array}$ & $\begin{array}{l}\text { Substa } \\
\text { Strengthening re } \\
\text { Strengthening re }\end{array}$ & $\begin{array}{l}\text { specific content (si } \\
\text { e self-efficacy, self } \\
\text { self-efficacy, self- }\end{array}$ & $\begin{array}{l}\text { s) } \\
\text { (Intervention I) } \\
\text { Intervention II) }\end{array}$ & \\
\hline
\end{tabular}

2.2.1 Substance-specific part: different teaching approaches

Only one teaching approach was applied per class, either a conventional learning at workstations, labelled as group 1 $(\mathrm{G} 1 ; \mathrm{n}=52)$, a modified guided moderated learning at workstations, labelled as group $2(\mathrm{G} 2 ; \mathrm{n}=74)$ or a traditional teacher-centered approach, labelled as group $3(\mathrm{G} 3 ; n=58$; Table 1). G2 was based on learning at workstation and was especially provided for low achievers for teaching the substance-specific content of cannabis. This approach achieved the best cognitive results as compared with G1 and G3 (Heyne \& Bogner, 2012).

\subsubsection{Substance-nonspecific part: influencing self-esteem}

Afterwards, the substance-unspecific content was taught in a student-centered learning environment. Two interventions were taught to all classes, students learning that self-esteem and resistance self-efficacy are decisive for strong self-confidence, and that self-confidence in turn is the best prevention against drug dependence (Table 1). To influence their self-esteem positively, teens should think about their own behaviour, discover individual skills, and win recognition from other students. Adapted from Wilms and Wilms (2007), self-esteem should be strengthened methodically through trust games, determining and describing skills and abilities, and through a written anonymous evaluation by peers. Methods targeting resistance self-efficacy are published elsewhere (Heyne \& Bogner, 2009).

2.2.3 Cluster analysis: determination of four consumption groups

We applied the CATI questionnaire (consumption, frequency of consumption, interest in consumption and curiosity about the effects) of the BZgA (2004) for purposes with regard to consumption behaviour and attitude. For grouping the students, we analyzed their response patterns by a cluster analysis (Appendix A). We applied two independent mathematical procedures whose contingency served as a quality criterion. We extracted a four-group classification using the agglomerative hierarchical Ward's method (Norusis, 1993). Given the cluster number as four, the following K-means cluster analysis procedure (Andersberg, 1973) assigned each student to one cluster, labelled PC, 
CC, EP and CO. A cluster-wise cross-tabulation of the two methods used evaluated this analysis and showed a high level of agreement of the four-cluster solution (adjusted coefficient of contingency $C_{k o r r}=.93, N=282, p<.001$ ). Clusters are homogenous if the standard deviations of each variable within each cluster are lower than the corresponding values in the sample as a whole (Bacher, 1994). Only one of the 16 within-cluster values $(6.25 \%)$ did not meet this criterion.

\subsection{Dependent Variable}

Self-esteem was measured using an 8-item psychometric scale in a pre- $\left(T_{1}\right)$, post- $\left(T_{2}\right)$ and retention test $\left(T_{3}\right)$ schedule (Götz, 2004). $T_{1}$ took place 1 week before intervention I, $T_{2}$ after completion of intervention II and $T_{3} 6$ weeks afterwards. No testing took place after the immediate completion of intervention I (as we did not expect any short-term changes). The self-esteem scale consisted of three items on general, positive self-esteem and of five items covering the issue of an individual desire to change him/herself, or to change feelings about him/herself. Cronbach's $\alpha$ was $\alpha_{\text {pre }}=.88, \alpha_{\text {post }}=.88$ and $\alpha_{\text {retention }}=.92$. Factor analyses (PCA with Varimax rotation confirmed the scale's unidimensionality in all test schedules (loading scores between 0.80 and 0.64). The Kaiser-Meyer-Olkin statistics were $.89, .89, .91$ respectively; and Bartlett's test of sphericity yielded Chi-square $=870.418,887.719,1287.552 ; \mathrm{df}$ $=28$ in each case; $\mathrm{p}<.001$ in each case.

We used non-parametric tests for statistical evaluation, because mean scores of all three tests were not normally distributed (Kolmogorov-Smirnov with Lilliefors Significance Correction, $\mathrm{p}<.001$ at $\mathrm{T}_{1}, \mathrm{~T}_{2}$ and $\mathrm{T}_{3}$ ). The Friedman test was used for in-group comparison. In case of significance, we applied the Wilcoxon test for pair-wise comparisons to determine the exact test date changes. The Kruskal-Wallis test was used for the comparison of our three independent samples. The Chi-Square value is reported when computing the Kruskal-Wallis test with SPSS 20. Finally, we employed the Mann-Whitney U test for inter-group differences (Zöfel, 2007). With a group size among 30 students no statistical tests were done.

The pre-test revealed baseline differences between boys and girls (Appendix B). Thus, sum scores could not be used in the comparison of gender for computing. We calculated difference variables to avoid this problem. These variables take into account the different base levels.

Statistical significance is partly dependent on the number of participants (Rost, 2013), for determining any pedagogical significance, the effect sizes need particular attention. We used Kraemer and Andrews (1982) measure of the non-parametric effect size D. Effect sizes of 0.2 are generally regarded as small; an effect size of 0.5 is considered as moderate and 0.8 as large (Cohen, 1988; Rost, 2013).

\section{Results}

\subsection{Total Group $(G)$}

Our educational intervention was associated with students' self-esteem over all test dates (Friedman Test, Chi-Square $=46.55 ; d f=2 ; p<.001)$. All testing schedules produced changes, although small effect size changes just existed between $T_{1}$ and $T_{3}$ as well as between $T_{2}$ and $T_{3}$ (Table 2). Control group scores did not differ at all (Wilcoxon, $Z=-1.568 ; p=.117$ ).

\subsection{Cluster Analysis}

Due to the different group sizes, no between-group comparisons were applied. The potentially curious cluster (PC; $n$ $=183$ ) made up $77.5 \%$ of the total sample and, thus, comprised the largest fraction of the sample which had never tried any drugs, showed almost no interest in drug consumption and detailed no curiosity about drug effects; additionally, they disapproved of any illegal drugs at all. The second cluster, the currently curious (CC; $n=34)$, had never tried any drugs, but was highly interested in their consumption and their effects; this cluster made up $14.4 \%$ of the total sample. The third cluster, the experimenters (EP; $n=15$ ), made up $6.4 \%$; they had tried drugs once or twice, were interested in consumption, but were less curious about their effects. The last cluster, the consumers $(\mathrm{CO} ; n=4)$, was identified by high consumption rates and a great interest in consumption; their curiosity about the effects had already dwindled. Fortunately, they comprised only 1.7\% (Heyne \& Bogner, 2009). 


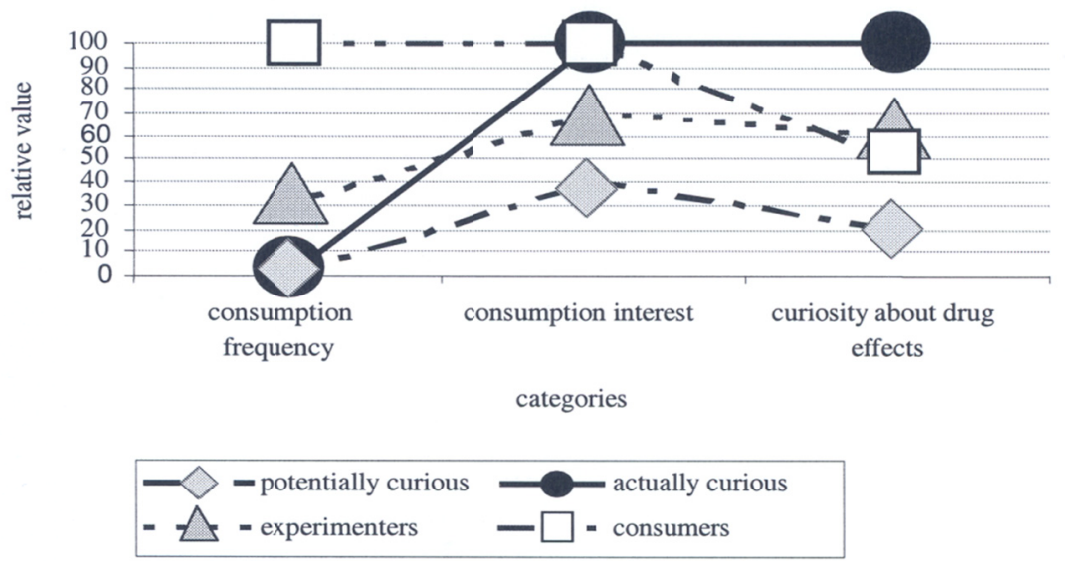

Figure 1: Characterization of the Four Clusters

\subsection{Consumption Groups}

All consumption groups revealed changes of the median scores over all test dates. The PC-, CC- and EP- cluster revealed these changes in spite of ceiling-effects (Appendix B).

The PC-cluster was the only consumption group that showed significant intervention effects (Friedman Test, Chi-Square $\left._{(\mathrm{PC})}=48.97 ; d f=2 ; p<.001\right)$. With regard to the effect size, pedagogically significant changes in self-esteem only occurred between the $T_{1}$ and the $T_{3}$ and between the $T_{2}$ and the $T_{3}$ schedules. The CC-cluster currently did not show any changes (Friedman Test, Chi-Square $(\mathrm{CC})=4.412 ; d f=2 ; p=.126$ ). No group effect was found (Table 2).

Due to the small sample size, no statistical calculations were done for both the EP- and the CO-cluster. The EP-Cluster showed a decline of self-esteem medians between the $T_{1}$ and the $T_{2}$ schedule and reached the basic value in $T_{3}$ again. The CO-Cluster revealed the smallest median score of all consumption groups in $T_{1}$, a further gradual decrease of self-esteem median scores was observed between the $T_{1}$ and $T_{2}$ and between the $T_{2}$ and the $T_{3}$ schedules (Appendix B).

\subsection{Gender}

Because of group size, gender effects could only be analyzed within the PC cluster. Both genders increased their self-esteem significantly (Friedman-Test, Chi-Square (PCfemale) $=22.29 ; d f=2 ; p<.001 ;$ Chi-Square $_{(\mathrm{PC} \text { (Pale) }}=26.75 ; d f$ $=2 ; p<.001)$. In pair-wise comparison, the effect sizes for girls $\left(\mathrm{PC}_{\mathrm{f}}\right)$ were small between $\mathrm{T}_{2}$ and $\mathrm{T}_{3}$ and between $\mathrm{T}_{1}$ and $\mathrm{T}_{3}$, the ones for boys $\left(\mathrm{PC}_{\mathrm{m}}\right)$ were moderate (Table 2). However the self-esteem shift were quite similar in both genders computing difference variables (Mann-Whitney $\mathrm{U}$ test; $Z_{\text {(T2-T1) }}=-0.195 ; p=.845 ; Z_{\text {(T3-T1) }}=-0.954 ; p=.340$; $\left.Z_{\text {(Т3-Т2) }}=-0.654 ; p=.513\right)$. Difference variable were computed, cause the pre-test showed baseline differences between boys and girls (Mann-Whitney $\mathrm{U}$ test; $Z_{(\mathrm{T} 1)}=-2.843 ; p=.013$; Appendix B).

\subsection{Teaching Methods}

The effect of the preceding teaching methods, too, could only be examined in the PC cluster. The self-esteem scores differed in $\mathrm{G}_{\mathrm{PC}}$ (student-centered) only between $\mathrm{T}_{1}$ and $\mathrm{T}_{3}$. In both other implementations, $\mathrm{G}_{\mathrm{PC}}$ (student-centered guided) and $\mathrm{G}_{\mathrm{PC}}$ (teacher-centered), changes in self-esteem occurred between $\mathrm{T}_{2}$ and $\mathrm{T}_{3}$ and between $\mathrm{T}_{1}$ and $\mathrm{T}_{3}$ (Figure 2, Table 2). Group size effects were excluded. No differences were found in the between-group comparison (Kruskal-Wallis-Test, Chi-Square $_{(\mathrm{PC}-\mathrm{T} 1)}=0.884 ; d f=2 ; p=.643 ;$ Chi-Square $_{(\mathrm{PC}-\mathrm{T} 2)}=2.127 ; d f=2 ; p=.345$; Chi-Square $\left._{(\mathrm{PC}-\mathrm{T} 3)}=1.276 ; d f=2 ; p=.528\right)$. 


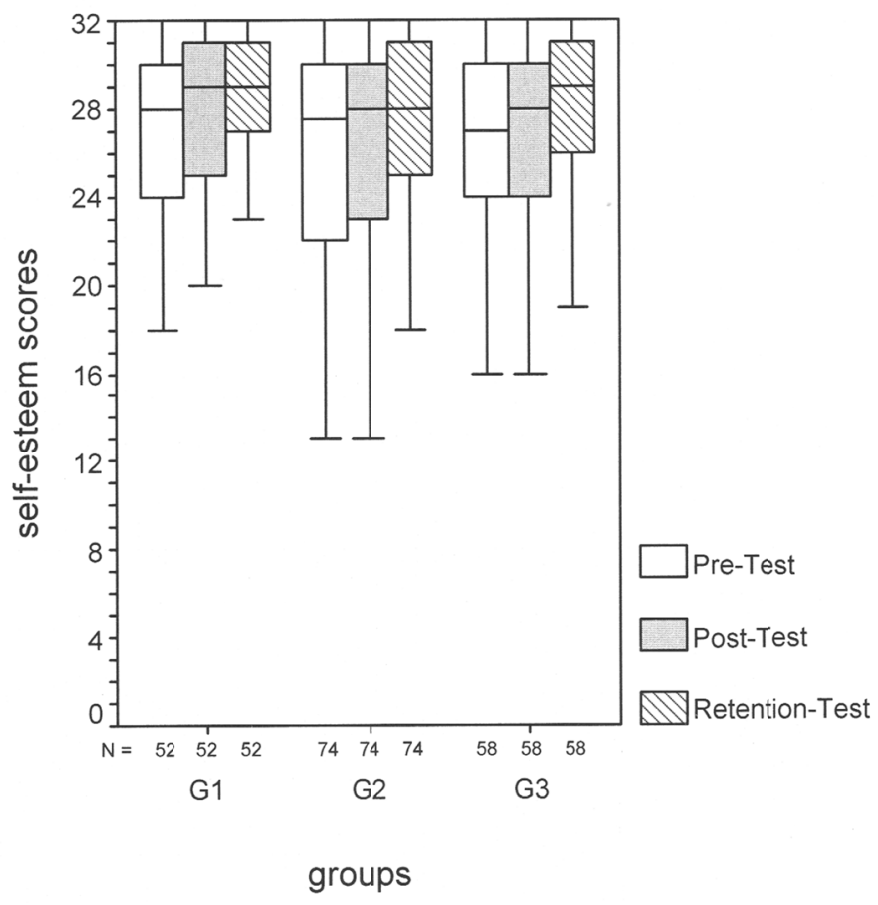

Figure 2: Changes in Self-esteem of the Potentially Curious Cluster (PC) in the Three Different Teaching Approaches $\mathrm{G} 1_{\mathrm{PC}}=$ student-centered; $\mathrm{G} 2_{\mathrm{PC}}=$ student-centered guided; $\mathrm{G} 3_{\mathrm{PC}}=$ teacher-centered

Table 2: In-Group Comparison of Self-Esteem of the Total Group (G), the Two Cluster Groups (PC, AC), Gender $\left(\mathrm{PC}_{\text {female }}, \mathrm{PC}_{\text {male }}\right)$ and the Different Teaching Methods ( $\left.\mathrm{G}_{\mathrm{PC}}, \mathrm{G} 2_{\mathrm{PC}}, \mathrm{G} 3_{\mathrm{PC}}\right)$ (Wilcoxon Test, asympt. sig., two-tailed); non-parametric effect size D

\begin{tabular}{|c|c|c|c|c|c|c|c|c|c|c|}
\hline \multirow[b]{3}{*}{ Groups } & \multirow[b]{3}{*}{ (n) } & \multicolumn{9}{|c|}{ Self-esteem change } \\
\hline & & \multicolumn{3}{|c|}{$\begin{array}{l}\text { Pre- vs. Posttest } \\
\qquad\left(T_{1}-T_{2}\right)\end{array}$} & \multicolumn{3}{|c|}{$\begin{array}{l}\text { Post- vs. Retention test } \\
\qquad\left(\mathrm{T}_{2}-\mathrm{T}_{3}\right)\end{array}$} & \multicolumn{3}{|c|}{$\begin{array}{l}\text { Pre- vs. Retention test } \\
\qquad\left(\mathrm{T}_{1}-\mathrm{T}_{3}\right)\end{array}$} \\
\hline & & $Z$ & $p$ & $D$ & $Z$ & $p$ & $D$ & $Z$ & $p$ & $D$ \\
\hline \multicolumn{11}{|c|}{ Total group } \\
\hline G & (236) & -2.742 & .006 & $--{ }^{b}$ & -4.104 & $<.001$ & .21 & -6.331 & $<.001$ & .34 \\
\hline \multicolumn{11}{|c|}{ Cluster groups } \\
\hline $\mathrm{PC}^{\mathrm{c}}$ & (183) & -2.474 & .013 & $--^{b}$ & -6.298 & $<.001$ & .24 & -4.788 & $<.001$ & .34 \\
\hline $\mathrm{CC}^{\mathrm{d}}$ & (34) & -.688 & .491 & A & -1.772 & .076 & $\beta$ & -.885 & .376 & A \\
\hline \multicolumn{11}{|c|}{ Gender } \\
\hline $\mathrm{PC}_{\text {female }}$ & $(86)$ & -1.556 & .120 & ${ }^{\beta}$ & -3.674 & $<.001$ & .39 & -4.509 & $<.001$ & .20 \\
\hline $\mathrm{PC}_{\text {male }}$ & $(97)$ & -1.924 & .054 & A & -3.093 & .002 & .53 & -4.454 & $<.001$ & .77 \\
\hline \multicolumn{11}{|c|}{ Teaching methods } \\
\hline $\mathrm{G}_{\mathrm{PC}}$ & $(52)$ & -1.807 & .071 & A & -1.686 & .092 & $\rho^{\mathrm{a}}$ & -3.614 & $<.001$ & .71 \\
\hline $\mathrm{G} 2_{\mathrm{PC}}$ & (74) & -1.515 & .130 & ${ }^{A}$ & -2.657 & .008 & .26 & -3.647 & $<.001$ & .36 \\
\hline $\mathrm{G} 3_{\mathrm{PC}}$ & (58) & -0.997 & .319 & ${ }^{A}$ & -3.904 & $<.001$ & .40 & -3.810 & $<.001$ & .43 \\
\hline
\end{tabular}

${ }^{a}$ not determined because of lacking significance. ${ }^{b}$ effect size $<0.2$. $^{c}$ potentially curious. ${ }^{d}$ currently curious. 


\subsection{Main Findings of the Study}

1) This life-skills-program influenced student's self-esteem positively.

2) The potentially curious cluster (PC) was the biggest consumption group and the only cluster which changed its self-esteem in a pedagogically significant manner. The currently curious cluster (CC) did not respond at all.

3) Girls showed lower self-esteem scores in the pre-test, however, pedagogical significance and effect sizes could be achieved for both genders.

4) Self-esteem of the potentially curious cluster (PC) was increased, irrespective of the different preceding teaching methods. The group size was still too small within the currently curious cluster (CC) to be able to present statistical results about the influence of the different teaching methods.

\section{Diskussion}

\subsection{The Biggest Consumption Group (PC) could be Influenced in Their Self-esteem Positively}

From a practical point of view, a pedagogically significant relationship between teens' self-esteem and the intervention occurred. We found a middle-term increase in the self-esteem of the sample as a whole. These results are in line with the findings of Botvin et al. (2003), Kähnert (2003) and Miller (1988). Successful intervention was demonstrated only for the potentially curious (PC) cluster. Due to its large group size, this group dominated the total group findings. Observed scores increased by only 2.0 medians between $\mathrm{T}_{1}$ and $\mathrm{T}_{3}$. Its effect size $\mathrm{D}$, however, identified a pedagogically significant effect. Authors such as Brown (1993) or Demo and Savin-Williams (1992) confirmed the pedagogical relevance of small changes even when ceiling-effects occur or relatively small changes were described. Zimmerman et al. (1997) pointed to a lower tendency for individuals with well-developed self-esteem to use addictive substances. It can be assumed that the already positive self-esteem of many potentially curious (PC) teens was further strengthened by our intervention. In addition, resistance self-efficacy could be influenced in this consumption group also positively and the already existing mind-sets about drugs were additionally supported by our intervention (Heyne \& Bogner, 2009).

\subsection{Gender-specific Teaching Seems not Required for Substance-specific Life Skills Programs}

The PC-cluster was also the only consumption group large enough to permit gender-specific analyses. However, the gender-specific differences in our pre-test scores are not easy to explain (Appendix B). Girls may feel less comfortable in low achieving classes which in itself may weaken their already fragile social standing and reputation. Additionally, their advanced puberty provides them with more realistic views compared to their male peers at this age. Kähnert (2003) analogously reported different pre-test results. The author found positive shifts in the long-run only for girls and boy's changes may not have been recordable due to a strong ceiling effect. Our girls indicated a small pedagogically significance in the medium-run, and the boys a probably artificial ceiling effect associated with moderate effect size. Obviously our female peers estimated their self-esteem level more realistically than our male peers. However, the difference variables may argue for a realistic assessment of both genders in our intervention and self-esteem changes were also measured for boys, despite coming from a high pre-test-level. Our third hypothesis was rejected, the educator's gender showing no effect.

\subsection{Teachers and External Experts should Work Together in Drug Prevention Programs}

The PC cluster over all treatment subgroups $\left(\mathrm{G}_{\mathrm{PC}}-\mathrm{G} 3_{\mathrm{PC}}\right)$ seemingly gained a pedagogical added value within our retention-test timeframe. In the middle-term, the preceding teaching approaches had no effect on the PC consumption group. $\mathrm{G}_{\mathrm{PC}}-\mathrm{G} 3_{\mathrm{PC}}$ revealed positive changes in their self-esteem. Nevertheless, the change processes over all test schedules needs further examination. In addition to the retention-test timeframe effect and in contradiction of our fourth hypothesis, a change occurred in the PC consumption group between the T-2 and T- 3 testing schedules under the implementation teacher-centered method $\mathrm{G}_{\mathrm{PC}}$. When comparing teacher-centered approaches with student-centered learning at workstations, many authors have reported lower scores with regard to interest, enjoyment, usage, usability of the content and cognitive knowledge of teacher-centered approaches (Heyne \& Bogner, 2012; Lord, 2001; Randler \& Bogner, 2006; Sturm \& Bogner, 2008). These results may have adversely affected follow-up measures in the self-esteem enhancement program. A possible explanation of this surprising result may lie in our using an external expert rather than the regular classroom teacher. Tobler and Stratton (1997) described external counsellors as particularly successful in prevention programs. It is possible that teens regard information by an external "expert" as more credible. The student-centered approach $\left(\mathrm{G} 1_{\mathrm{PC}}\right)$ confirmed these 
conclusions. No influence of self-esteem training was found for this sub-group in the post-test. $\mathrm{G} 1_{\mathrm{PC}}$ students were cognitively overloaded in the preceding substance specific part of our intervention (Heyne \& Bogner, 2012). This inappropriate teaching approach substantially delayed the effectiveness of the subsequent self-esteem intervention in the short-term. The negative effect disappeared in the middle-term. Obviously the male educator conducting both self-esteem interventions succeeded in eradicating the negative experiences of the preceding substance-specific section.

The modified guided student-centered approach $\left(\mathrm{G} 2_{\mathrm{PC}}\right)$ performed best in the substance-specific part and enabled the teens to generate opinions independently of adults (Heyne \& Bogner, 2012). This group also showed post-test changes in the self-esteem enhancement program and appeared considering also the good results in self-efficacy training all together the best approach (Heyne \& Bogner, 2009).

Considering these results teachers and external experts should work together in drug prevention programs. Teachers provide didactical know how, i.e. in the field of knowledge acquisition in open learning environments and external experts ensure requirement objectivity in other parts of substance-specific life skills programs.

\subsection{Students of the Current Curious Cluster (CC) Could not be Influenced in Their Self-esteem}

No positive changes were observed in the currently curious cluster (CC), even though such prevention programs are also said to target teens considered as a risk group for harmful behaviour (Kähnert, 2003). Thus, the findings are in line with our second hypothesis. The PC and CC cluster responded differently to the measures of our life skills program. The resistance self-efficacy training revealed also no influence to the cluster of the CC students (Heyne \& Bogner, 2009).

Small subsample sizes prevented testing our last hypothesis, that the preceding constructivist student-oriented teaching methods would influence the mind-sets of these teens and that they would react positively to the self-esteem measures.

\section{Conclusions}

The potentially curious cluster's self-esteem (PC) can be successfully supported by a substance-specific life skills program adapted to the requirements of the syllabus. This teaching approach reaches the majority of students who already reject drug use and promotes self-esteem of boys and girls similarly. Considering this consumption group, promotion of self-esteem should be linked with basic instruction about drugs and resistance self-efficacy training (Heyne \& Bogner, 2009). With regard to the whole intervention, substance-specific and substance-nonspecific treatments should be provided by external experts as well as teachers. However, an increase in individual self-esteem requires a continuous educational process involving repeated instruction during a school year. For a continuous implementation beyond the basic programs, specific training for pre- and in-service teachers seems appropriate

However, we have to be aware that educational approaches do not reach all students, i.e. the cluster of the current curious (CC) needs additional and different intervention. Subsequent studies should design prevention programs especially for this target group and should evaluate whether current curious students (CC), consumer (CO) and experimenter (EP) can be summarised to one target group. Because only few of these at-risk students are in one single class, youngsters from several classes should be summarized to a group and are informed specifically for target group. Consequently, teachers have to assume the responsibility for the identification and grouping of these at-risk students. Considering this consumption group, measures to increase self-esteem should be separated stringent from substance-specific contents in order to achieve success. At the same time the effects of the different teaching methods we have presented should be investigated also for this consumption groups.

\section{Limitations of the Study}

1) Self-esteem itself is considered as unsteady in the developmental phase of teens (Kähnert, 2003). Observation over a longer period of time is desirable; but probably not realisable because of organizational, financial and time limitations.

2) The educational intervention was associated with students' self-esteem significantly, but we could not interview a representative sample of PC-students to assess how the intervention influenced their self-esteem due to official barriers. 
3) Due to the small sample sizes no statistical conclusions about experimenter (EP) and consumer (CO) could be extracted.

\section{Acknowledgment}

We welcome the cooperation of the teachers and students involved in this study as well as we are very thankful to F.-J. Scharfenberg, A. Ash and M. Wiseman for valuable discussions and reading the text.

\section{References}

Andersberg, M.R. (1973). Cluster analysis for applications. New York: Academic Press.

Bacher, J. (1994). Clusteranalyse Anwendungsorientierte Einführung (Cluster analysis. Application-oriented introduction). München, Germany: R. Oldenbourg.

Botvin, G.J., \& Dusenbury, L. (1998). Substance Abuse Prevention and Promotion of Competence. In Bond, L.A., \& Compas, B.E. (Eds.), Primary Prevention in the School. Primary Prevention of psychopathology (Vol. 12, pp. 146-178). California: Sage.

Botvin, G.J., Baker, E., Dusenbury, L., Botvin, E.M., \& Diaz, T. (1995). Longterm followup results of a randomized drug abuse prevention trial in a white middle-class population. Journal of the American Medical Association, 273(14), 1106-1112. http://dx.doi.org/10.1001/jama.1995.03520380042033

Botvin, G.J., Griffin, K.W., Paul, E., \& Macaulay, A.P. (2003). Preventing tobacco and alcohol use among elementary school students through life skills training. Journal of Child and Adolescent Substance Abuse, 12(4), 1-18. http://dx.doi.org/10.1300/J029v12n04_01

Branden, N. (2001). The psychology of self-esteem: a revolutionary approach to self-understanding that launched a new era in modern psychology. San Francisco: Jossey-Bass, 2001.

Brown, J.D. (1993). Self-esteem and self-evaluation: Feeling is believing. In Suls, J. (Ed.), Psychological perspectives on the self (Vol. 4, pp. 27-58). Hillsdale, NJ: Erlbaum.

Bynner, J.M., O`Malley, P.M., \& Bachman, J.C. (1981). Self-esteem and delinquency revisited. Journal of Youth and Adolescence, 10, 407-441. http://dx.doi.org/10.1007/BF02087937

Cohen, J. (1988). Statistical power analysis for the behavioral science. Hillsdale, NJ: Erlbaum.

Covington, M. (1984). The motive for self-worth. In Ames, R., \& Ames, C. (Eds.), Research on motivation in education - Student motivation (Vol. 1). New York: Academic Press.

Cuijpers, P. (2002). Effective ingredients of school-based drug prevention programs. A systematic review. Addictive Behaviors, 27, 1009-1023. http://dx.doi.org/10.1016/S0306-4603(02)00295-2

Demo, D.H., \& Savin-Williams, R.C. (1992). Self-concept stability and change during adolescence. In Lipka, R.P., \& Brinthaupt, T.M. (Eds.), Self-perspectives across the life span. New York: State University of New York Press.

Duit, R., Gropengießer, H., \& Kattmann, U. (2005). Towards science education research that is relevant for improving practice: The model of educational reconstruction. In Fischer, H. (Ed.), Developing Standards in Research on Science Education (pp. 1-9). London: Taylor \& Francis.

Durlak, J.A. (1995). School based prevention programs for children and adolescents. Thousand Oaks: Sage.

Freitag, M., Kähnert, H., \& Hurrelmann, K. (1999). Gesundheits- und drogenpolitische Schlussfolgerungen für Familie, Schule und Gesellschaft [Health- and drug-political conclusions for family, school and society]. In Freitag, M., \& Hurrelmann, K. (Eds.), Illegale Alltagsdrogen. Cannabis, Ecstasy, Speed und LDS im Jugendalter [Illegal drugs. Cannabis, ecstasy, speed and LSD in adolescence] (pp. 203-235). Weinheim, Germany: Juventa.

German Federal Centre of Health Education (2004). Die Drogenaffinität Jugendlicher in der Bundesrepublik Deutschland. Eine Wiederholungsbefragung der BZgA [The drug affinity of youngsters in Germany. A recurringsurvey of the $B Z g A]$. Köln, Germany: Bundeszentrale für gesundheitliche Aufklärung (BZgA).

Gottfredson, D.C., Jones, E.M., \& Gore, T.W. (2002). Implementation and Evaluation of a cognitive-behavioral intervention to prevent problem behavior in a disorganized school. Preventive Science, 3(1), 43-56. http://dx.doi.org/10.1023/A:1014671310038 
Götz, T. (2004). Emotionales Erleben und selbstreguliertes Lernen bei Schülern im Fach Mathematik [State-emotions and self-regulated learning in mathematics]. München, Germany: Dissertation. Universität München.

Hansen, W.B., Graham, J.W., Wolkenstein, B.H., \& Rohrbach L.A. (1991). Program integrity as a moderator of prevention program effectiveness: Results for fifth-grade students in the adolescent alcohol prevention trial. Journal of Studies on Alcohol and Drugs, 52, 568-579.

Harter, S. (1986). Cognitive-developmental processes in the integration of concepts about emotions and the self. Social Cognition, 4, 119-151. http://dx.doi.org/10.1521/soco.1986.4.2.119

Harter, S. (1990). Self and identity development. In Feldman, S.S., \& Elliott, G.R. (Eds.), At the threshold: The developing adolescent. Cambridge, MA: Harvard University Press.

Harter, S. (1999). The construction of the self: A developmental perspective. New York: Guilford Press.

Hattie, J. (1992). Self-concept. Hillsdale, NJ: Erlbaum.

Heyne, T., \& Bogner, F. X. (2009). Strengthening resistance self-efficacy: Influence of teaching approaches and gender on different consumption groups. Journal of Drug Education, 39, 439-457. http://dx.doi.org/10.2190/DE.39.4.f

Heyne, T., \& Bogner, F. X. (2012). Guided Learning at Workstations about Drug Prevention with Low Achievers in Health Education. World Journal of Education, online published. http://dx.doi.org/10.5430/wje.v2n6p1

Hirsch, B.J., \& DuBois, D.L. (1991). Self-esteem in early adolescence: The identification and prediction of contrasting longitudinal trajectories. Journal of Youth and Adolescence, 20, 53-72. http://dx.doi.org/10.1007/BF01537351

Kähnert, H. (2003). Evaluation des schulischen Lebenskompetenzprogramms "Erwachsen werden” [Evaluation of the life skills program „, Growing up”. Bielefeld, Germany: Dissertation. Universität Bielefeld.

Kazdin, A.E., French, N.H., Unis, A.S., \& Esveldt-Dawson, K. (1983). Helplessness, depression, and suicide intent among psychiatrically disturbed inpatient children. Journal of Conculting and Clincal Psychology, 51, 504-510.

Kember, D., \& Gow, L. (1994). Orientations to teaching and their effect on the quality of student learning. Journal of Higher Education, 65, 58-74.

Kolip, P. (1999). Programme gegen Sucht [Programs against dependence]. Weinheim, Germany: Juventa.

Kraemer, H.C., \& Andrews, G. (1982). A nonparametic technique for meta-analysis effect size calculation. Psychological Bulletin, 91(2), 404-412.

Lienert, G.A., \& Raatz, U. (1998). Testaufbau und Testanalyse [Test construction and test analysis]. Weinheim, Germany: Psychologie.

Lord, T. R. (2001). 101 Reasons for Using Cooperative Learning in Biology Teaching. The American Biology Teacher, 63, 30-38. http://dx.doi.org/10.1662/0002-7685(2001)063[0030:RFUCLI]2.0.CO;2

Miller, R.L. (1988). Positive self-esteem and alcohol/drug related attitudes among school children. Journal of Alcohol and Drug Education, 33, 26-31.

Mittag, W., \& Jerusalem, M. (1999). Gesundheitsförderung bei Kindern und Jugendlichen [Health promotion for kids and adolescents]. In Röhrle, B., \& Sommer, G. (Eds.), Prävention und Gesundheitsförderung [Prevention and Health Promotion] (pp. 162-194). Tübingen, Germany: Dgvt Verlag.

Neumark-Sztainer, D., Story, M., French, S.A., \& Resnick, M.D. (1997). Psychosocial correlates of health compromising behaviors among adolescents. Health Education Research, 12, 37-52. http://dx.doi.org/10.1093/her/12.1.37

Newcomb, M.D., Maddahian, E., \& Bentler, P.M. (1986). Risk factors for drug use among adolescents: concurrent and longitudinal analyses. American Journal of Public Health, 76, 525-531.

Norusis, M.J. (1993). SPSS for Windows professional statistics release 6.0. Chicago: SPSS Inc.

Randler, C., \& Bogner, F. X. (2006). Cognitive achievement in identification skills. Journal of Biological Education, 40, 1-5. http://dx.doi.org/10.1080/00219266.2006.9656038

Reinherz, H.Z., Stewart-Berghauer, G., Pakiz, B., Frost, A.K., Moeykens, B.A., \& Holmes, W.M. (1989). The relationship of early risk and current mediators to depressive symptomatology in adolescence. Journal of the 
American Academy of Child and Adolescent Psychiatry, 28, 942-947. http://dx.doi.org/10.1097/00004583-198911000-00021

Rosenberg, M. (1986). Self-concept from middle childhood through adolescence. In Suls, J., \& Greenwald, A.G. (Eds.), Psychological perspectives on the self (pp. 107-136). Hillsdale, NJ: Erlbaum.

Rosenberg, M., Schooler, C., \& Schoenbach, C. (1989). Self-esteem and adolescent problems: Modeling reciprocal effects. American Sociological review, 54, 1004-1018.

Rost, D.H. (2013). Interpretation und Bewertung pädagogisch-psychologischer Studien [Interpretation and assessment of educational-psychological studies]. Weinheim und Basal, Germany: Beltz.

Scheier, L.M., Botvin, G.J., \& Griffin, K.W. (2001). Preventive intervention effects on developmental progression in drug use: structural equation modeling analyses using longitudinal data. Preventive Science, 2(2), 91-112. http://dx.doi.org/10.1023/A:1011543730566

Selnov, G.W. (1985). Using a stratified approach in substance intervention and prevention programs among adolescents: An empirical analysis. Journal of Drug Education, 15, 327-341. http://dx.doi.org/10.2190/BBA3-FE34-M9UH-WNA3

Stacy, A.U., Newcomb, M.D., \& Bentler, P.M. (1992). Interactive and higher-order effects of social influences on drug use. Journal Health Social Behav., 33, 226-241.

Sturm, H., \& Bogner, F. X. (2008). Student-oriented versus teacher-centered: The effect of learning at workstations about birds and bird flight on cognitive achievement and motivation. International Journal of Science Education, 30, 941-959. http://dx.doi.org/10.1080/09500690701313995

Tobler, N.S. (1986). Meta-analysis of 143 adolescent drug prevention programs: quantitative outcome results of program participants compared to a control or comparison group. Journal of Drug Issues, 16(4), 537-567.

Tobler, N.S., \& Stratton, H.S. (1997). Effectiveness of school-based drug prevention programs: A meta analysis of the research. The Journal of Primary Prevention, 18, 71-128. http://dx.doi.org/10.1023/A:1024630205999

Tobler, N.S., Roona, M.R., Ochshorn, P., Marshall, D.G., Streke, A.V., \& Stackpole, K.M. (2000). School-based adolescent drug prevention programs: 1998 Meta-Analysis. The Journal of Primary Prevention, 20(4), 275-336. http://dx.doi.org/10.1023/A:1021314704811

Wells, L.E., \& Rankin, J.H. (1983). Self-concept as a mediating factor in delinquency. Social Psychology Quarterly, 46, 11-22.

Wilms, H., \& Wilms, E. (2007). Erwachsen werden: Life-Skills-Programm für Schülerinnen und Schüler der Sekundarstufe I [Growing up: Life skills programs for students]. Wiesbaden, Germany: Schürmann + Klagges.

World Health Organization. (1994). Life Skills Education in schools. Geneva: WHO.

Zimmerman, M.A., Copeland, L.A., Shope, J.T., \& Dielman, T.E. (1997). A longitudinal study of self-esteem: Implications for adolescent development. Journal of Youth and Adolescence, 26(2), 117-141. http://dx.doi.org/10.1023/A:1024596313925

Zöfel, P. (2007). Statistik verstehen. Ein Begleitbuch zur computergestützten Anwendung. [UnderstandingStatistics. An accompanying book for computer-supported utilization]. München, Germany: Adison-Wesley.

\section{Appendix A}

\begin{tabular}{lcccccc}
\hline & Cannabis & Amphetamin & LSD & Heroin & Cocaine & Ecstasy \\
\hline Knowledge about (\%) & 97.9 & 74.2 & 66.4 & 95.8 & 96.2 & 88.1 \\
Supply (\%) & 10.6 & 2.1 & 1.3 & 0 & 0.8 & 1.3 \\
Consumption (\%) & 8.1 & 0,8 & 0.8 & 0 & 0.8 & 1.3 \\
Interest in consumption (\%) & 13.6 & 4.7 & 5.9 & 3.4 & 5.9 & 7.6 \\
Curiosity about effects (\%) & 16.9 & 11.4 & 9.7 & 5.9 & 8.1 & 13.1 \\
\hline
\end{tabular}

Consumption Attitudes and Behaviour Regarding Illegal Drugs ( $M=13.6$ years; $N=282)$. 


\section{Appendix B}

\begin{tabular}{|c|c|c|c|c|c|c|c|}
\hline \multirow[b]{4}{*}{ Groups } & \multirow[b]{4}{*}{$(n)$} & \multicolumn{6}{|c|}{ Self-esteem change } \\
\hline & & \multicolumn{2}{|c|}{$\mathrm{T}_{1}$} & \multicolumn{2}{|c|}{$\mathrm{T}_{2}$} & \multicolumn{2}{|r|}{$\mathrm{T}_{3}$} \\
\hline & & Median & $(25 / 75$ th $P)$ & Median & $(25 / 75$ th $P)$ & Median & $(25 / 75$ th $P)$ \\
\hline & & \multicolumn{6}{|c|}{ Total group } \\
\hline \multirow[t]{2}{*}{$\mathrm{G}$} & $(236)$ & 27.00 & $(23.00 / 29.00)$ & 28.00 & $(23.00 / 30.00)$ & 29.00 & $(25.00 / 31.00)$ \\
\hline & & \multicolumn{6}{|c|}{ Cluster groups } \\
\hline $\mathrm{PC}$ & $(183)$ & 27.00 & $(24.00 / 30.00)$ & 28.00 & $(24.00 / 30.00)$ & 29.00 & $(26.00 / 31.00)$ \\
\hline $\mathrm{CC}$ & (34) & 26.00 & $(21.75 / 28.25)$ & 27.00 & $(21.50 / 29.00)$ & 27.50 & $(22.50 / 30.00)$ \\
\hline EP & $(15)$ & 28.00 & $(16.00 / 30.00)$ & 24.00 & $(20.00 / 31.00)$ & 28.00 & $(19.00 / 30.00)$ \\
\hline \multirow[t]{2}{*}{$\mathrm{CO}$} & (4) & 21.50 & $(11.25 / 26,50)$ & 16.00 & $(15.00 / 22.25)$ & 14.50 & $(09.00 / 25.25)$ \\
\hline & & \multicolumn{6}{|c|}{ Gender } \\
\hline $\mathrm{PC}_{\text {female }}$ & $(86)$ & 26.00 & $(22.75 / 29.00)$ & 27.00 & $(23.00 / 29.00)$ & 28.00 & $(25.00 / 30.00)$ \\
\hline \multirow[t]{2}{*}{$\mathrm{PC}_{\text {male }}$} & $(97)$ & 28.00 & $(25.00 / 30.00)$ & 29.00 & $(25.00 / 31.00)$ & 30.00 & $(27.00 / 32.00)$ \\
\hline & & \multicolumn{6}{|c|}{ Teaching approaches } \\
\hline $\mathrm{G} 1_{\mathrm{PC}}$ & $(52)$ & 28.00 & $(24.00 / 30.00)$ & 29.00 & $(25.00 / 31.00)$ & 29.00 & $(27.00 / 31.00)$ \\
\hline $\mathrm{G} 2_{\mathrm{PC}}$ & $(74)$ & 27.50 & $(22.00 / 30.00)$ & 28.00 & $(23.00 / 30.00)$ & 28.00 & $(25.00 / 31.00)$ \\
\hline $\mathrm{G} 3_{\mathrm{PC}}$ & $(57)$ & 27.00 & $(24.00 / 30.00)$ & 28.00 & $(24.00 / 30.00)$ & 29.00 & $(26.00 / 31.00)$ \\
\hline
\end{tabular}

Grouped Median and 25./75.th Percentile of

* the total group $(\mathrm{G})$

* the four cluster groups (PC, CC, EP, CO)

* gender $\left(\mathrm{PC}_{\text {female }}, \mathrm{PC}_{\text {male }}\right)$

* the different teaching approaches $\left(\mathrm{G} 1_{\mathrm{PC}}, \mathrm{G} 2_{\mathrm{PC}}, \mathrm{G} 3_{\mathrm{PC}}\right)$ 